\title{
Becoming a reflective environmental educator: Students' insights on the benefits of reflective practice
}

Author names

Location

(Received $x x x x$; final version received $x x x x$ )

Having the capacity for reflective practice is considered a key attribute of a successful environmental educator. In this paper we discuss how we used a range of exercises with environmental education students within the Master of Environmental Education for Sustainability program at Griffith University to develop their capacity for reflective practice. Evidence of impact and long-term effects of the experience were obtained using data from samples of student coursework exercises and assessment, along with the results of a post-program survey, Results indicate that the exercises did indeed succeed in empowering students to (a) clearly reflect on their personal and professional intentions, (b) better understand the effect of these on their practice in the field, and (c) continue to reflect on their practice post-Masters program.

Keywords: reflective practice, environmental education, education for sustainability

\section{Defining the field of environmental education}

Since its inception in the late 1960s, the field of environmental education has undergone expansive discussion, critique, modification and even titular variations to evolve into its contemporary state (Bader, 2004; Fien, 1993a; Gough, 2006; Marcinkowski, 2010; Tilbury, 1995; UNESCO-UNEP, 1978). To provide context to the study reported on in this paper, it is necessary to highlight some of the key characteristics of this field. Now often referred to as Education for Sustainability, the field of environmental education is socio-critical (Ferreira, 2009) and focuses on building individual and community capacity to be environmental citizens, demonstrated through their personal and social actions (Bader, 2004; Fien, 1993a; Huckle, 1993; Payne, 2006; Tilbury, 1995). 
Critical thinking and reflection are thus considered key capacities and processes in environmental education (Tilbury, 1995), with many suggesting that critical analysis and questioning of values on any given topic or situation leads to reflection and ultimately a shift in thinking and attitudes (Fien, 1993a; Hickson, 2011; Payne, 2006; Tilbury, 1995; UNESCO-UNEP, 1978). With critical thinking and reflection deeply embedded in environmental education theory, key principles and practice, it follows that these should be evident in programs aiming to educate prospective environmental educators.

\section{Reflective practice for environmental educators}

It is clear from the reflective practice literature that reflection increases learning and improves professional practice, in particular, in relation to critical thinking and an increased commitment to effective action (Fien \& Rawling, 1996; Gardner, 2009; Grant, 1984; Merryfield, 1993; Reynolds, 2011; Zeichner \& Teitelbaum, 1982). Indeed, this has been widely recognised, particularly in the field of professional development (Gardner, 2009; Jurin \& Hutchinson, 2005; Ottesen, 2007; Reynolds, 2011; Rogers, 2001; Schön, 1983). According to Fien and Rawling (1996, p. 8), 'reflective practitioners are [thus] aware of the impact on others and society of their work, the institutional press of the environments in which they work, and the moral and ethical consequences of their decisions and actions'.

Reflective practice, therefore, is also an attractive idea for environmental educators as it provides a process for achieving key goals of environmental education, namely, the development of critical thinking skills and a commitment to action. Furthermore, it has the potential to awaken environmental educators to the social change objectives of their field and also to recognise the opportunities and constraints in 
the ideological and institutional contexts within which they currently work or may work in the future. Indeed, as Reynolds $(2011$, p. 8) notes,

[r]eflection needs to be more than a consideration of the technical and organisational aspects of presenting problems. It should also mean raising social, political and cultural issues, questioning purposes and intentions, and if necessary, challenging the assumptions and taken-for-granteds on which organisational policies and practices are based.

This is true for environmental educators also. Stevenson and Sterling (2010, p. 235) argue that environmental educators:

should be cognizant of advances in theories of learning that might continue to inform their research or practice concerning learning and learners, while at the same time using their own experiences and enquiries to question and advance these same theories, especially as they relate to the particular processes, substance, contexts and challenges of environment-related learning.

This reflects Schön's (1983) thinking on the tacit knowledge and experiences of professionals, which Merryfield (1993, p. 28) calls the "worldview of themselves, diverse peoples and the workings of the world'. Using this worldview as a starting point for reflection provides a platform from which practitioners can question and advance their 'own actions and effects and the ideas or theories-in-use that shape their action strategies' (Osterman \& Kottkamp, 1993, p. 2). However, as Hobbs (2007) argues, critical reflective practice is a skill for which capacity must be built.

Ecological identity work, such as that outlined by Thomashow (1995), is one way in which environmental educators can develop their capacity for reflective practice. Since 'the goal of reflective practice is to understand the consequences of professional activities ... and to connect those activities to one's value system' (Thomashow, 1995, 
p. 164), we argue that in environmental education, reflective practice is a key strategy through which individuals are able to craft for themselves an ecological identity.

Thomashow has developed a number of activities for educators to use as a means to 'show how an ecological worldview can be used to interpret personal experience, and how that interpretation leads to new ways of understanding personal identity' (Thomashow, 1995, p. 2). He argues these activities are 'a powerful means to bridge the inner and outer life of the environmentalist' (Thomashow, 1995, p. xiv). Jurin and Hutchinson (2005, p. 436) provide further evidence in support of such activities by stating that they allow participants to 'gain perceptions of themselves within their perceptions of their environment, especially when coupled with a guided process that encourage(s) reflective thinking'. The same argument has also been made by others, for example, Pavlovich (2007) and Bleakley (2000). In this paper, we examine a cohort of environmental education students who engaged in a series of specially designed exercises, including ecological identity exercises, to ascertain if this work was effective in developing their skills and capacities in reflective practice.

\section{The study}

\section{Study context}

The Griffith University Master of Environmental Education for Sustainability program is designed as a professional development program, with students either mid-career professionals who work in schools, for state and local governments, for non-government organisations, or are young graduates wanting to work in the field but with limited practical experience in the field. There are four core courses in the program. This paper focuses on the course, Education, Sustainability and Social Change, which explores the interplay of economic, social and political factors in the processes of education and 
social change in order to develop socially transformative approaches to environmental education. This course is the final core course the students undertake.

As part of this course, students complete a series of seven exercises that seek to develop their capacity for reflective practice. These exercises are a combination of:

- an exercise developed by the course coordinators to enable students to reflect on the 'context' of their own lives;

- four exercises from Thomashow's (1995) book Ecological identity: Becoming a reflective environmentalist, to develop students' understandings of their ecological identities and;

- two exercises adapted from surveys relating to socio-environmental and educational beliefs (Fien, 1993b).

Together, these reflective practice exercises provide students with opportunities to assess their personal commitment to the environment and sustainability, as well as to understand the interacting personal and contextual factors that guide their personal and professional practices as reflective environmental educators. Table 1 provides an overview of each exercise, noting how each works to build students' capacity for reflective practice. Exercise 1 has been developed by the course coordinators, exercises 2-5 are ecological identity exercises from Thomashow (1995), while exercises 6 and 7 are adaptations of Fien (1993b).

Insert Table 1: Reflective practice exercises

Through these exercises, students are thus able to reflect on how their identity has been shaped, what nurtures it, and in what direction it is growing. Students record their responses to the exercises and use these to prepare a final assessment piece, in which they are encouraged to be creative. In the final assessment task, students present 
a synthesis of their learning about: their ecological identity; their capacity for reflective practice; the social change theory they have engaged with throughout the four core courses in the Masters program; their professional and personal practices; and what actions they plan to take into the future.

\section{Study aim}

The aim of our study was to identify the impact of the course on students' personal and professional lives, and how it engaged them in reflective practice. We knew from our annual course evaluations that students enjoyed undertaking the exercises and the final assessment. We also knew that some students found these exercises challenging. Having no empirical evidence about the impact of the exercises and assessment item on their ability to be reflective environmental educators and individuals post-course, however, raised a number of questions:

(1) What is the student experience of undertaking the reflective practice exercises and how might the experience be improved?

(2) Does completing the reflective practice exercises assist students to make links between the educational and social change theories presented in the program and their own practices as environmental educators?

(3) Do the reflective practice exercises encourage students to become reflective environmental educators over the long term?

Being able to answer these questions would enable us to understand how effective the course is in building students' capacities for reflective practice.

\section{Method}

The primary data source for this study comes from a survey of students who had 
completed the course in the previous 6 years (2005 to 2010 inclusive). This method was chosen as it was time and cost effective, could be easily distributed to a large audience, and allowed for both quantitative and qualitative data to be collected and analysed. All students who completed the course (92) were mailed a survey with a reminder 6 weeks later. As we mailed the surveys to students' last known addresses, a number of surveys (27) were returned to sender. Of the surveys we assume were delivered (65), 29 responses were received - a response rate of just under $50 \%$. We did not survey students post-2010, to allow for at least one year post-course to have elapsed, given our interest in the longer-term impact of the course.

The initial survey was developed based on our own involvement and experiences as teachers of the course, through reference to a previous study of the course (Fien \& Rawling, 1996), and after reviewing annual course evaluation documentation. The survey questionnaire consisted of 10 questions, 5 scaled and 5 open-ended. The questions asked about students' initial response to the task of doing the reflective practice exercises, perceived barriers to completing the exercises and the assignment, students' feelings after completing the course, students' abilities to link theory and practice, whether they were now acting as reflective practitioners, and their ongoing commitment to social change. A secondary data source was also utilised in the form of their final assessment pieces to provide additional insights into students' linking theory and practice. In line with ethical requirements to de-identify data, the assignments and surveys were not matched. Data from student assignments are thus denoted numerically (1), while extracts from student surveys are denoted by a letter (A).

Qualitative responses were collated and reviewed by the researchers. An interpretive-descriptive approach using the constant comparative method (Corbin \& Strauss, 2008) of data analysis was employed. Interpretive-descriptive research is exploratory and reliant on people's words and meanings (Maykut \& Moorhouse, 1994; 
Shkedi, 2005). As such, the researchers employed an iterative process in which responses were read and re-read to determine recurring themes with negotiation of categories and meanings until agreement was reached. Data for each quantitative question were collated using a Likert scale.

\section{Results and discussion}

The research results are presented and discussed below, by research question.

\section{Student experience of undertaking the reflective practice exercises}

\section{A: Results}

Initial response. Students' initial responses to the idea of undertaking reflective practice exercises were of three types: pleasure, resistance/apprehension, and neutral. Of the 29 students who completed this question, the majority (20 students $-69 \%)$ responded positively with responses ranging from 'at last, an easy assessment item' (Student W) to 'I thought it would be a breeze' (Student X) and 'I looked forward to the experience. I enjoyed the opportunity for a more subjective course component' (Student K). Other students reported feeling that it would be fun, with many looking forward to the opportunity to do something that was not common in an academic environment. For example, Student D’s response was 'I was excited - it was close to having fun!'.

There were, however, also a number of students (5 students $-18 \%$ ) who felt apprehensive. For example, one student noted that they felt the task was 'too personal, too hard, I'm not the one who needs to reflect' (Student N), while another 'worried that [they] would have little to write' (Student V). Of these five respondents, two felt they were already quite reflective. For example, one student said they 'wondered if it was necessary, as I would already have considered myself to be a reflective person' (Student S). Three students (11\%) indicated that they were neutral about the tasks. One student 
responded 'it was just part of the class' (Student A), another that 'it was a course requirement and just had to be done' (Student U). In line with these views, another student saw the exercises simply as a way to 'take notes for the assessment' (Student O).

Response after completion. While students' initial responses to the idea of undertaking the exercises and assignment varied from pleasure or neutral to apprehension, the responses after completing the course were more uniform. Students on the whole (26 students - 90\%) reported feeling more positive after completing the exercises than they did at the beginning of the course. They reported (i) a better understanding of self, (ii) a sense that the exercises opened their minds to different views, (iii) that the task was engaging, and (iv) that the exercises had led them to reflect on and change their practice.

For many students, the exercises gave them a clearer self-awareness. For example, Student I said, 'I felt very refreshed after the exercises since I could give myself time to think about myself and see myself from another angle. It helped me to place myself in the context of the environment, and to see how my past experiences have coloured my present'. Another student noted that the exercises 'provoked deep memories - I felt I understood more about my personal evolution to becoming a concerned citizen. Even four years on, that exploration remains vividly with me' (Student D). Student O fully understood the purpose of the exercises and assignment, as their comment illustrates: 'It was actually a meta-cognition exercise to look inside and answer some questions about the way I am, I think, I feel'.

Students also felt that the exercises had opened their minds to different views, as Student A's comment illustrates: 'The exercises were very valuable in prompting me to think of issues in different ways'. The exercises allowed students to 'work through a 
process that opens your mind to different ideas, visions and beliefs' (Student $\mathrm{H}$ ) and offered a 'wide range of opportunities to expand knowledge and see what other students' unique opinions are' (Student M).

It was obvious from the majority of responses that students found the task particularly engaging. As Student A reported: 'I always kept thinking about the exercises long after completing them - I was engaged in the process'. Others found them 'thought-provoking' (Student B), 'rewarding' (Student G), and 'motivating' (Student N). Student T 'enjoyed the experience. It gave me an opportunity to undertake a project very different to others I had ever done'.

Although most students felt that the exercises and assessment item were a positive experience, some students indicated that the experience was very challenging. Issues such as motivation, distance and trust were identified by these students as barriers to their full engagement with the process.

Motivation. Some students found it difficult to motivate themselves to engage with the exercises because they struggled to see the value of reflection, particularly in an academic setting where memorising content is often seen as more important than personal development. Student J stated, for example, that they felt 'like the course content work was more important'.

Distance. The course is also offered to students studying in distance education mode. Many of these students felt that they would have benefited from interaction with other students. Comments included: 'As an external student, I found the inability to discuss issues face-to-face was a bit of a hindrance' (Student W), and 'as an external student, I find studying in isolation more challenging than studying internally. I think discussions or seeing other students' work/ideas would be beneficial' (Student H). 
Trust. Creating a safe and trustworthy environment also emerged as an issue for some students, particularly those who found the experience challenging. For example, one student said '[a]t the time it was very difficult. I had to face issues I had pushed to the back of my mind. Now I am glad I went through this growth process. When sharing information that is private and intimate, you need a safe environment. You need to trust those you are sharing yourself with' (Student L).

\section{$1 B$ Discussion}

The first questions of the survey sought to collect data on students' feelings about undertaking the reflective exercises to supplement our personal experiences and course evaluations reflecting students' positivity about the exercises. The results of our study demonstrate positive reactions from students in response to the reflective practice process experienced through the course, with 26 students (90\%) reporting they felt more positive after completion of the exercises. The statements presented in the results highlight a number of outcomes relating to the development of students' capacity for reflective practice.

The comments made by Students $\mathrm{D}, \mathrm{I}$ and $\mathrm{O}$ in the results show recognition of changes in their professional and personal ideology over time and provide evidence of the reflection process described in the literature by Schön (1983) in that they display an awareness of their worldview and how it shapes their identity (Stenberg, 2010). In addition to clearer awareness, there is also evidence of students exploring their identity through opening their minds to different views, as described by Students $\mathrm{H}$ and $\mathrm{M}$ above.

However, our study also identified a number of barriers to the reflective practice exercises. While 9 students (30\%) indicated there were no barriers, others 
acknowledged motivation, distance, and trust as challenges faced throughout the process.

Motivation. The exercises presented as part of this course were not typical in the academic environment. This presents us with a unique challenge: reflective practice is typically a part of professional development (Osterman \& Kottkamp, 1993; Stenberg, 2010; Thomashow, 1995) rather than academic assessment, with limited literature on this issue. Fien and Rawling (1996) and Hobbs (2007) do, however, suggest that the assessment of reflective practice activities can be out of place due to the personal nature of such deep reflection. This may account for some of the motivation issues experienced by students. We continue to grapple with the issue of how to assess such student work.

Distance. Distance education students, with whom we have no face-to-face contact, present a unique challenge. As Osterman and Kottkamp (1993, p. 2) note, reflective practice 'is neither a solitary nor a relaxed meditative process'. Rogers (2001, p. 43) goes further: 'if the environment lacks autonomy, feedback, opportunities for connection to others and appropriate challenge, reflection is unlikely to occur'. In order to overcome some of the challenges our distance education students face, we have begun to use an online 'live classroom'.

Trust. Students identified trust as a potential barrier to engaging in reflection. The challenge for educators is to provide a safe environment where students feel able to share their feelings with their colleagues. Rogers (2001, p. 46), in discussing Schön's (1983) reflective practice, states: 'Key to Schön's reflective practice is the role of coach or mentor who seeks to guide students in developing habits of reflective practice by establishing a mutual dialogue that involves processes such as listening, telling, 
demonstrating and imitating'. In our teaching, we take care to discuss the sensitive nature of these activities at the start of semester to create a community of trust amongst students and between students and lecturers. Facilitated classes over the course of a semester provide students with time and opportunity to discuss their observations with one another. Further, these exercises are undertaken at the end of the Masters program so students have already developed a relationship with one another and with the lecturers.

\section{Does completing the reflective practice exercises assist students to make links} between the educational and social change theories presented in the program and their own practices as environmental educators?

\section{$2 A$ Results}

A key purpose of the reflective practice assignment is to help students to link theories that they have encountered through the Masters program with their practice as environmental educators. They do this through drawing on their reflective practice exercises, academic readings, and on discussions that have taken place throughout the program. In this study we utilised final student assignments along with their own recollections to obtain evidence that students had understood and made the links between environmental education theory and their practice as environmental educators.

We found that most students were able to identify where they locate themselves in the theoretical scale of environmental ideologies and values developed by Pepper (1996) along with where that fits in either the Dominant Social Paradigm or New Environmental Paradigm (Dunlap, Van Liere, Mertig, \& Jones, 2000). Another example of students being able to link theory and practice was seen in how students described the influence of particular readings, pedagogical techniques and learning experiences on their view of themselves as environmental educators. As Student 4 stated, 'I have learnt 
the importance of critical, social and cooperative learning embedded in meaningful problem solving issues and the holistic nature of environmental education'. The future vision that students created for themselves included descriptions of how they believed their personal ideologies influenced their educative practice. For example, Student 8 , who was working as a school teacher at the time, wrote:

The desire to help develop [my] students' environmental consciences and attitudes as their teacher is probably what is helping to forge my own ecological identity ... I do believe that collective citizen action is necessary for real change and I am slowly adopting inherently the attitudes and values I espouse to my students.

It is clear that the reflective practice exercises also allowed students to identify and acknowledge the gaps they saw between theory and practice, and to reflect on their attempts to reconcile this gap. Student 13 explained this as:

My environmental self and my oneness with the universe have some distance still to travel. As discovered through my course questionnaire, I am still not operating sustainably at a high level in my home and community environment ... This is certainly a rhetoric/reality gap and can only be explained I think by the fact that change, in values and attitudes, cannot happen overnight.

Students' comments also indicated that they were able to identify that this link has occurred. As Student W notes: 'The exercises were designed to help us think critically about social change theories'. For Student B, it was clear that ' $[\mathrm{t}] \mathrm{he}$ assignment was a reflective process, examining my own personal thoughts, interacting with the readings, and where I hope to go with my environmental work in the future', while for Student F:

[t]he whole process somehow led me inexorably toward reflecting on whole-system change. My three areas of endeavour: as an educator, as a visual artist and as an environmental activist, blurred to form a larger picture and I have had a number of talks with peers and others about how to work most effectively towards sustainability. 
Students also reported that they had changed their practice as a result of the exercises and assignment. Student N realized 'the worth of reflection and evaluation' and now 'incorporate[s] [reflection] into my teaching'. Student G has changed his practices and is still 'following the plan re personal and professional development' outlined in his assignment. The depth of change that some students experience is encapsulated by Student S's comment:

I re-assessed the way I taught both students and even my own children. I realised that it is not the facts that are important but to bring about openness to critical thinking practices. I felt that I had also undergone a change in recognising that personal responsibility for learning was a key element in the teaching, or should I say, facilitation process.

Students' reflections also raised deep questions about the role and purpose of their career and, for some, initiated career changes. For example, one student, while enjoying the reflection and assessment item immensely, expressed disappointment about how limiting a secondary school where he works is in integrating environmental education. This was an issue that become apparent to him - and distressed him through completing the exercises and assignment. It is interesting to note that this student has since moved out of secondary education and is now working full-time as an environmental educator with an NGO. As he said, 'the course made me realise I was being undervalued and ineffective in the school I was in. The reflective process empowered me to see my value' (Student Q).

\section{B Discussion}

Yip (2007, p. 295) suggests that reflection enables practitioners 'to bridge the gap between their intended mindfulness and unconsciousness in practice'. In our study we found that reflective environmental educators do indeed have the potential to bridge the 
gap between their educative intentions as socio-critical environmental educators and their unconscious professional ideologies, personal motivations and inherent worldviews, that is, the gap between theory and practice. This notion is supported by the comments made by students in their final assessment pieces (see comments by Students $4,8 \& 13$ above), where they were able to provide examples of how their practice has been influenced by theory and how it will influence their future direction as practitioners. Students G, N and S also provide examples of how their course experience has shaped their personal and professional development.

Such findings indicate questioning and advancement by students of the theories that shape their actions, which Osterman and Kottkamp (1993) describe as elements of critical reflection. Student statements also indicate visions of a future identity, another piece of the reflective practice puzzle (Beauchamp \& Thomas, 2010). The students' experience of the reflective practice exercises can be summarized by the following statement by Stenberg (2010, p. 332): 'if student teachers are given the opportunities to reflect on their actions and life experiences and to expand their insights and understanding, then they have a chance to become more aware of beliefs, values and understandings that underlie decision making in their teaching practice'. As a result of our study, we know that, for our students, the reflection process enables new connections to be made between theory and practice and that the reflective practice exercises have encouraged new ways of understanding their role in environmental, educational and social change.

\title{
3. Do the reflective practice exercises encourage students to sustain their capacity for reflective practice over the long term?
}

\author{
3 A Results
}

*Email contact: 
In the reflective practice assignment, students outlined their plans for personal behaviour change, increased action-taking and increased community engagement. In our study, we asked students about the extent to which the reflective practice process had encouraged them actually to change their behaviour, commit to taking action for the environment, and whether it had made them more interested in engaging with their local community.

Ten students (35\%) who responded to the survey said that they had made personal behaviour changes, 14 students $(50 \%)$ said that the course had given them the confidence to take action for the environment and 20 students $(70 \%)$ responded that they had become more engaged in their local community as a result of the reflective practice process. All 29 students who responded (100\%) agreed that the process had improved their capacity for reflective practice to some extent, with $20 \%$ (6 students) indicating that it had very much improved their capacity and their practice..

\section{B Discussion}

The low response rate of 10 students $(35 \%)$ stating their behaviour had changed as a result of the course possibly reflects that these students were already behaving in an environmentally aware manner before undertaking the course. More promising results in relation to action (14 students - 50\%) and community engagement (20 students - $70 \%$ ) were evident amongst students. This response may reflect a broadening of students' overall understanding of action-taking from the purely personal to the civic and community-based. In addition, we found that the future vision or plan students developed for themselves has in many instances continued to be used by students to reflect on their current practice and future plans. With all students surveyed reporting improvement, these results strongly indicate that such exercises do support the development of reflective practice capacity over the long term. The implications of 
these findings are particularly relevant for environmental educators as it is clear that reflective practice provides a means to incorporate moral and ethical criteria to address relationships between professional practice and wider social contexts. Such a process is a critical part of shaping and affirming environmental educators' identity with respect to the social change objectives of the field.

\section{Conclusion}

We know that environmental educators, given the nature of their work, will face many challenges in their efforts to educate for social change. It is, therefore, crucial that they have the capacity for reflective practice to help them to deal with the challenges they will inevitably face. As Fien (1993, p. 98) notes, the hallmark of a transformative [environmental educator] is her and his 'inner life', that commitment to ecological and social justice and transformation, which is sustained not only by moral outrage (and we do need our share of that) but also by the habit of critical reflection upon one's views and work.

This study examined the impact of reflective practice exercises on the professional development of a cohort of environmental educators. Findings indicate that reflective practice processes and the use of reflective practice exercises does enable students to articulate their personal and professional intentions and actions in relation to environmental education, sustainability and social change. We found that the course did build capacity and encourage individuals to be reflective practitioners who are able to link theory to their own practice. This clearly indicates that reflective practice exercises are a successful strategy for developing reflective environmental educators.

The study also identified a number of barriers relating to motivation, distance and trust. We have begun to address these through an on-line 'live classroom' and 
through greater attention to the development of a community of trust between lecturers and students and amongst the student cohort. Despite these barriers, however, our study indicates that the reflective practice exercises our students undertake do assist them to become reflective environmental educators in way that is sustained over time. 


\section{References}

Bader, B. (2004). Epistemological renewal and environmental education: Science in context. Australian Journal of Environmental Education, 20(2), 13-22.

Beauchamp, C., \& Thomas, L. (2010). Reflecting on an ideal: Student teachers envision a future identity. Reflective Practice, 11(5), 631-643.

Bleakley, A. (2000). Writing with invisible ink: Narrative, confessionalism and reflective practice. Reflective Practice, 1(1), 11-24.

Corbin, J. M., \& Strauss, A. L. (2008). Basics of qualitative research: Techniques and procedures for developing grounded theory. Los Angeles: SAGE Publications.

Dunlap, R. E., Van Liere, K. D., Mertig, A. G., \& Jones, R. E. (2000). Measuring endorsement of the new ecological paradigm: A revised NEP scale. The Journal of Social Issues, 56(3), 425-442.

Ferreira, J. (2009). Unsettling orthodoxies: Education for the environment/ for sustainability. Environmental Education Research, 15(5), 607-620.

Fien, J. (1993a). Education for the environment: Critical curriculum theorising and environmental education. Geelong: Deakin University.

Fien, J. (1993b). Environmental Education and Social Change: Study Guide and Reader. Geelong: Deakin University.

Fien, J., \& Rawling, R. (1996). Reflective practice: A case study of professional development for environmental education. The Journal of Environmental Education, 27(3), 11-20.

Gardner, F. (2009). Affirming values: Using critical reflection to explore meaning and professional practice. Reflective Practice, 10(2), 179-190.

Gough, A. (2006). A long, winding (and rocky) road to environmental education for sustainability in 2006. Australian Journal of Environmental Education, 22(1), 71-76.

Grant, C. (1984). Preparing for reflective teaching. New York: Allyn \& Bacon.

Hickson, H. (2011). Critical reflection: Reflecting on learning to be reflective. Reflective Practice, 12(6), 829-839.

Hobbs, V. (2007). Faking it or hating it: Can reflective practice be forced? Reflective Practice, 8(3), 405-417.

Huckle, J. (1993). Environmental education and sustainability: A view from critical theory. In J. Fien (Ed.), Environmental education: A pathway to sustainability (pp. 43-68). Geelong: Deakin University. 
Jurin, R., \& Hutchinson, S. (2005). Worldviews in transition: Using ecological autobiographies to explore students' worldviews. Environmental Education Research, 11(5), 485-501.

Marcinkowski, T. J. (2010). Contemporary challenges and opportunities in environmental education: Where are we headed and what deserves our attention? Journal of Environmental Education, 41(1), 34-54.

Maykut, P., \& Moorhouse, R. (1994). Beginning qualitative research: A philosophical and practical guide. London: The Falmer Press.

Merryfield, M. (1993). Reflective practice in global education: Strategies for teacher educators. Theory into Practice, 32(1), 27-32.

Osterman, K. F., \& Kottkamp, R. B. (1993). Reflective practice for educators: Improving schooling through professional development. Newbury Park, CA: Corwin Press.

Ottesen, E. (2007). Reflection in teacher education. Reflective Practice, 8(1), 31-46.

Palmer, J. A., \& Suggate, J. (1996). Influences and experiences affecting the proenvironmental behaviour of educators. Environmental Education Research, 2(1), 109-121.

Palmer, J. A., Suggate, J., Robottom, I., \& Hart, P. (1999). Significant life experiences and formative influences on the development of adults' environmental awareness in the UK, Australia and Canada. Environmental Education Research, 5(2), 181-200.

Pavlovich, K. (2007). The development of reflective practice through student journals. Higher Education Research and Development, 26(3), 281-295.

Payne, P. G. (2006). Environmental education and curriculum theory. The Journal of Environmental Education, 37(2), 25-35.

Pepper, D. (1996). Modern environmentalism: An introduction. London: Routledge.

Reynolds, M. (2011). Reflective practice: Origins and interpretations. Action Learning: Research and Practice, 8(1), 5-13.

Rogers, R. (2001). Reflection in higher education: A concept analysis. Innovative Higher Education, 26(1), 37-57.

Schön, D. (1983). The reflective practitioner: How professionals think in action. New York: Basic Books.

Shkedi, A. (2005). Multiple case narrative: A qualitative approach to studying multiple populations. Netherlands: John Benjamins Publishing Company. 
Stenberg, K. (2010). Identity work as a tool for promoting the professional development of student teachers. Reflective Practice, 11(3), 331-346.

Stevenson, R. B. (with Stirling, C.). (2010). Environmental learning and agency in diverse educational and cultural contexts. In R. Stevenson \& J. Dillon (Eds.), Engaging environmental education: Learning, culture, and agency (pp. 219238). Rotterdam: Sense Publishers.

Thomashow, M. (1995). Ecological identity: Becoming a reflective environmentalist. Cambridge, MA: The MIT Press.

Tilbury, D. (1995). Environmental education for sustainability: Defining the new focus of environmental education in the 1990s. Environmental Education Research, 1(2), 195-212.

UNESCO-UNEP. (1978). The Tbilisi Declaration. Connect, 3(1), 1-8.

Yip, K. (2007). Self-reflection in reflective practice: A Jaspers' orientation. Reflective Practice, 8(2), 285-298.

Zeichner, K., \& Teitelbaum, K. (1982). Personalised and inquiry-oriented teacher education: Analysis of two approaches to the development of curriculum for field based experience. Journal of Education for Teaching. 8(2), 95-117. 